\title{
Spanish Translation, Face Validity, and Reliability of the ICIQ-B Questionnaire with Colorectal Cancer Patients
}

\author{
Cinara Sacomori ${ }^{1,6(0)}$ Luz Alejandra Lorca ${ }^{2(0)}$ Mónica Martinez-Mardones ${ }^{3,4(0)}$ Paulina Benavente ${ }^{3(0)}$ \\ Jorge Plasser 3 ,70 Megan Pardoe ${ }^{50}$
}

${ }^{1}$ Escuela de Kinesiología, Universidad Bernardo O’Higgins, Santiago,

Address for correspondence Cinara Sacomori, PT, PhD, Avenida Viel Chile

${ }^{2}$ Servicio de Medicina Física y Rehabilitación, Hospital del Salvador, 1.467, Santiago, Chile (e-mail: csacomori@yahoo.com.br).

Santiago, Chile

${ }^{3}$ Servicio de Cirugía, Hospital del Salvador, Santiago, Chile

${ }^{4}$ Escuela de Medicina, Universidad Finnis Terrae, Santiago, Chile

${ }^{5} \mathrm{ICIQ}$ Group, Bristol Urological Institute, Southmead Hospital, Bristol, United Kingdom

${ }^{6}$ Facultad de Medicina Clinica Alemana Universidad del Desarrollo, Santiago, Chile

${ }^{7}$ Instituto Oncológico Fundación Arturo Lopez Pérez, Santiago, Chile

J Coloproctol 2021;41(4):340-347.

\begin{abstract}
Keywords

- bowel function

- fecal incontinence

- colorectal neoplasms

- validation study

- surveys and questionnaires
\end{abstract}

Purpose To describe the English-to-Spanish translation process and preliminary psychometric analysis (face validity, cultural adaptation, and test-retest reliability) of the International Consultation on Incontinence Questionnaire - Bowels Module (ICIQB) among Chilean colorectal cancer patients.

Materials and Methods The face validity was studied with 10 colorectal cancer patients, and the test-retest reliability, with 15 patients, 1 month before and 6 months after cancer surgery.

Results Two rounds of translation/back translation resulted in a Spanish version. The English expression open your bowels was translated as defecar, as it is easily understandable in Spanish. The patients reported that the instrument was easy to answer, with clear instructions, and that it was adequate to appraise their health condition. The testretest reliability was good (Spearman rho $[\rho] \geq 0.842$ ); only item 15a, the Bristol Stool Scale, obtained a moderate correlation $(\rho=0.639)$. The patients reported a variety of symptoms, including increased bowel movements, nocturnal bowel movements, fecal urgency, and incontinence.

Conclusions The first Spanish version of the ICIQ-B was culturally adapted for Chilean colorectal cancer patients, and showed good test-retest reliability. It might be a reference for other Spanish-speaking countries and for patients with other conditions. The ICIQ-B is a robust comprehensive questionnaire for bowel function. received

December 16, 2020 accepted after revision June 15, 2021
DOI https://doi.org/ 10.1055/s-0041-1736639. ISSN 2237-9363.

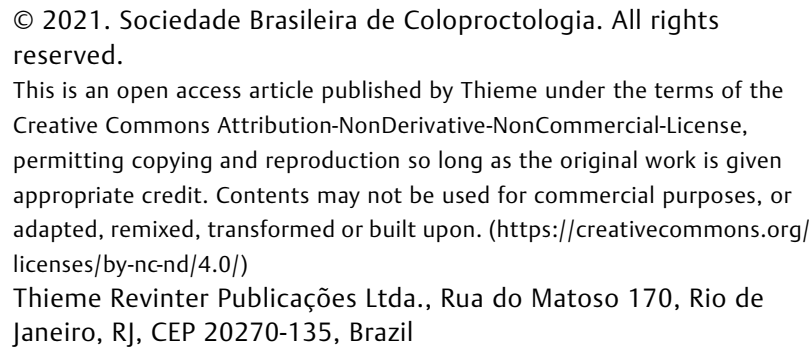
reserved.

This is an open access article published by Thieme under the terms of the Creative Commons Attribution-NonDerivative-NonCommercial-License, permitting copying and reproduction so long as the original work is given appropriate credit. Contents may not be used for commercial purposes, or adapted, remixed, transformed or built upon. (https://creativecommons.org/ licenses/by-nc-nd/4.0/)

Thieme Revinter Publicações Ltda., Rua do Matoso 170, Rio de Janeiro, RJ, CEP 20270-135, Brazil 


\section{Introduction}

Colorectal cancer is the world's fourth most deadly cancer (after lung, liver, and stomach cancer), and is most common in developed countries. Its incidence has continued to rise in countries with a medium-high human development index ${ }^{1}$ and in young people. It is associated with physical inactivity, obesity, high consumption of red and/or processed meats, smoking, and alcohol consumption. ${ }^{2}$

Colorectal cancer may produce many bowel symptoms which have a negative impact on functioning and quality of life (QoL). ${ }^{3-5}$ Prior to treatments, patients usually report changes in bowel habits, such as the frequency of defecation, the consistency and shape of the stool, and difficulty in evacuation; all of these symptoms are usually called constipation or diarrhea. ${ }^{5}$ New surgical techniques for colorectal cancer have been proposed to prevent ostomy and maintain continence. ${ }^{6,7}$ However, incontinence episodes might be a problem and impair QoL. Low anterior resection, in particular, which is one of the most indicated treatments for rectal cancer, has been associated with a $42 \%$ prevalence of low anterior resection syndrome (LARS). This syndrome includes symptoms of incontinence (fecal and flatus), urgency, diarrhea, and increased bowel movements. ${ }^{7}$

Recently, efforts have been made to develop survivorship care plans aiming to cover follow-up care and control of disease progression. ${ }^{8}$ The use of validated questionnaires facilitates patient control and strengthens the continuum of care. Among the instruments used to assess bowel function and fecal incontinence in people with colorectal cancer, the most used are the Vaizey score ${ }^{9}$ and the Wexner continence score. ${ }^{10}$ These scales are short and quite easy to apply, but assess only the severity of the incontinence. In contrast, the colorectal module of the European Organization for Research and Treatment of Cancer QoL Questionnaire - Colorectal (EORTC QLQ-CR38 or-CR29) and the Gastrointestinal Quality of Life Index also assess bowel function and QoL. ${ }^{11,12}$ However, a study ${ }^{13}$ showed that neither the EORTC Core (C)-30 nor the CR-38 were sensitive to explain the differences in bowel function in patients with rectal cancer.

The International Consultation on Incontinence Questionnaire - Bowel Module (ICIQ-B) has been proposed as a more specific and comprehensive patient report outcome (PRO) measure, as it includes an analysis of bowel pattern, bowel control, other bowel symptoms, sexual impact, and QoL. ${ }^{14,15}$ The ICIQ-B seems to provide a more in-depth comprehension of the phenomenon of "bowel function." A recent study ${ }^{16}$ demonstrated that the online and paper versions of the ICIQB had robust psychometrics (test-retest reliability, internal consistency, and convergent validity) for use among male and female US citizens, including Veterans. However, this questionnaire was not yet available in Spanish. Therefore, the aim of the present study was to describe the translation process and preliminary psychometric analysis (face validity, cultural adaptation, and test-retest reliability) of the Spanish version of the ICIQ-B among Chilean colorectal cancer patients.

\section{Materials and Methods}

This translation and validation study had three phases: 1) translation and back translation; 2) face validity, cultural adaptation, and consensus with the ICIQ group regarding possible changes; and 3) test-retest reliability analysis.

\section{Target Population and Participant Sampling}

The target population was colorectal cancer patients, who usually suffer from bowel symptoms. The participants of the face validity and test-retest reliability analyses were adult patients with colorectal cancer undergoing treatment at Hospital del Salvador, Santiago de Chile, whose native language was Spanish. They were evaluated approximately onemonth pre surgery or until six-months post-surgical tumor resection. Selection was targeted at a representative sample in terms of gender, type of cancer, age, and level of schooling. Patients were excluded if they presented ostomy, neurological conditions, or cognitive impairments.

The present study was approved by the Ethical Review Board at Hospital del Salvador, Santiago de Chile on May 28, 2019. Informed consent was obtained from all participants.

\section{Instrument}

The ICIQ-B is an instrument that assesses fecal incontinence symptoms and how they impact QoL. It is divided into 3 domains with scores from 1 to 21 for bowel patterns, 0 to 28 for bowel control, and 0 to 26 for QoL related to bowel symptoms; the higher the score, the worse the bowel pattern, the bowel control, or QoL. ${ }^{14,15}$

It was developed in United Kingdom, but still lacked a Spanish version. Its English version has proven to be robust and psychometrically solid, following analyses of its content, construct, criterion validity, internal consistency, and reliability. ${ }^{14,15}$ We obtained permission from the ICIQ group to translate this questionnaire into Spanish and validate it in Chile.

\section{Translation and Back Translation}

The translation of the questionnaire from English to Spanish was performed by a native Chilean Spanish speaker, a health professional fluent in English and with a master's degree obtained in Australia. The back translation was performed by a British translator currently living in Chile, fluent in Spanish and with a bachelor of arts in Spanish and master's degree in applied translation studies obtained in England. The back translation was sent to the original authors (ICIQ group), who deliberated which questions did not retain the original meaning. These questions were reviewed by researchers and the Spanish translator, and, finally, an updated back translation into English was submitted, until the entire back translation version kept the meaning of the original and was approved by the ICIQ group.

\section{Face Validity}

Face validity was assessed through interviews with patients and observations of patients filling out draft versions of the questionnaires. First, we observed six patients answering the 
questionnaire, and soon after we interviewed them. Second, these patients' suggestions were discussed with the ICIQ group to adapt the translated version. After some modifications, we applied the questionnaire to four more patients.

We used the following questions to guide patient interviews after they had filled out the questionnaire: "How easy or difficult did you find the questionnaire to complete? Were there any words, phrases or terms that were unfamiliar, ambiguous, or difficult to understand? If so, which and why? Were the items clear? If not, which ones and why? Were the instructions clear? If not, which ones and why? Did you object to answering any items? If so, which ones and why? Were any of the response categories unclear, inappropriate, or inadequate to enable you to express what you felt? If so, which ones and why? Are there any further comments you would like to make or items you would like to ask about?"

\section{Test-Retest Reliability Analysis}

Aiming to evaluate stability, we performed a test-retest analysis, in which the questionnaire was applied to the same set of respondents twice with an interval of one week. This interval between evaluations was chosen because most of the patients were at prehabilitation for surgery, and the test and retest should be performed under the same condition. Due to the contingency of coronavirus disease 2019 (COVID-19), we used for the test-retest reliability an initial in-person evaluation, when patients attended to receive the prehabilitation kit (incentive spirometer, elastic bands, pedometer, and educational materials). The retest evaluation was performed by telephone interview. For those patients recruited after surgery, both test and retest assessments were performed by telephone interview.

\section{Data Analysis}

Data was analyzed with the Statisgtical Package for the Social Sciences (IBM SPSS Statistics for Windows, IBM Corp., Armonk, NY, United States) software, version 23.0, using descriptive statistics, which were reported as numbers and percentages for the categoric variables, and as means, medians and standard deviations (SDs) for the continuous variables. The changes in the translation and back-translation were analyzed on a comparative table. For the test-retest reliability analysis, we performed a Spearman correlation test with $p<0.05$.

\section{Results}

\section{Translation and Back Translation}

After the process of independent translation, the two versions were compared by the original authors (the ICIQ group), who deliberated which questions did not retain the original meaning. The few differences observed in the word preferences in the translation process are described on -Table 1. For item 3, we decided to maintain the term "to defecate/defecar" instead of "open your bowels" throughout the Spanish version of the questionnaire because it is more comprehensible in Chile.

\section{Face Validity}

We included 10 patients with colorectal cancer, most of them older adults (age: mean $=69.7$ years; $S D=10.5$ years; range $=51$ to 86 years), who had different levels of schooling (-Table 2).

The first 6 (100\%) patients interviewed reported they found the instrument easy to answer, with truly clear instructions, and that the questionnaire was very adequate to evaluate their health condition with regards to their colorectal cancer. Three of them (50\%) had difficulties answering questions 9,10 or 12 , as they did not present stool or mucous leaks, so they felt the need to add an option that said "not applicable" or "I don't have leakage." After reaching a consensus with the ICIQ group, we decided not to make these changes, as the 'Always' response ensured that their lack of leakage was reflected.

In question 17, 3 patients (50\%) reported that the fragment "is in your mind the possibility..." ("Pasa por su mente la posibilidad...") was not clear. This question was revised by both translators and changed to "Are you ever worried about the possibility of suffering an accidental bowel leak?”. (¿Piensas en la posibilidad de tener escape accidental de deposiciones?).

In question 3, only 2 patients answered in the column asking about the symptoms when the condition is "at worst." They reported it was difficult to understand, or they simply did not see the column. The ICIQ group recommended to mantain this part of the questionnaire in the current form, as the non-responses would not affect the final score of the domain. After this revision, in a second round of interviews, we applied the new version of the instrument to four more patients. They felt the instrument was clear, and that there was no need for further changes.

\section{Test-Retest Reliability}

- Table 3 shows the characteristics of test-retest participants. The correlations obtained from test-retest analysis ( - Table 4) were strong for most of the items (Spearman rho $[\rho] \geq 0.842 ; p>0.001)$; and 32 of 42 items showed perfect correlations $(\rho=1.0)$. Only item 15a, the Bristol Stool Scale, showed a moderate correlation between the test and retest measures $(\rho=0.639 ; p>0.001)$. The scores of the questionnaire domains also showed strong correlations between test and retest $(\rho \geq 0.972 ; p>0.001)$.

\section{Description of Bowel Pattern, Bowel Control, and Quality of Life Domains}

Regarding bowel pattern, the mean score for all participants $(n=25)$ was $6.2( \pm 3.1)$; for rectal cancer patients, it was 6.1 $( \pm 3.4)$; and, for colon cancer patients, it was $6.2( \pm 3.1)$. Meanwhile, the mean score regarding bowel control was 5.8 ( \pm 6.3 ) for all participants, 5.4 ( \pm 7.5 ) for rectal cancer patients, and $6.1( \pm 5.8)$ for those with colon cancer. The QoL score was $8.3( \pm 8.5)$ for all participants, $6.1( \pm 8.7)$ for rectal cancer patients, and $9.6( \pm 8.4)$ for those with colon cancer.

The patients reported a variety of symptoms, including: increased bowel movements (20\% defecating 3 or more times per day), nocturnal bowel movement ( $40 \%$ needing to defecate at least once during sleep), fecal urgency (rarely $=24 \%$; 
ICIQ-B Spanish Version Sacomori et al. 343

\begin{tabular}{|c|c|c|c|c|c|c|c|c|c|}
\hline 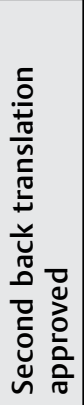 & 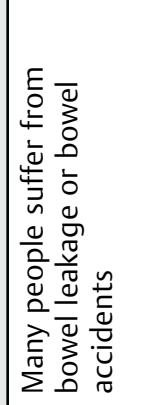 & 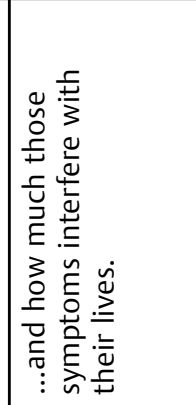 & 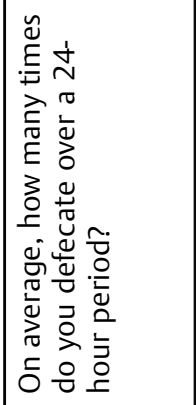 & 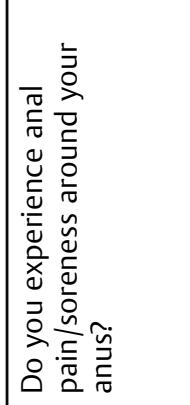 & 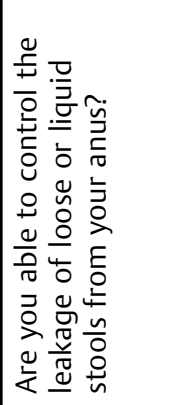 & 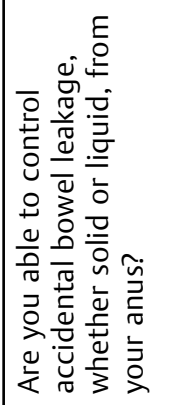 & 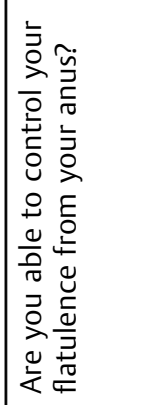 & 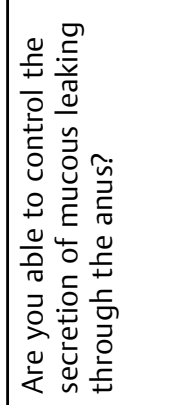 & 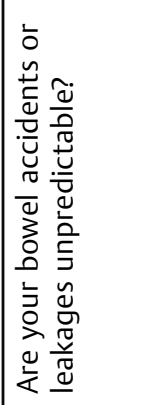 \\
\hline 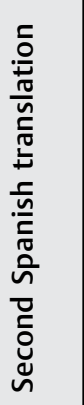 & 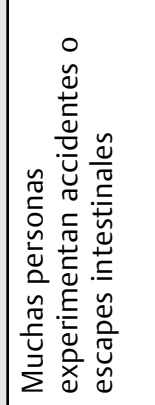 & 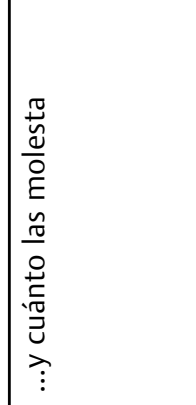 & 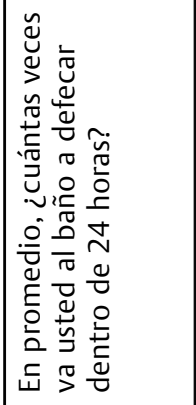 & 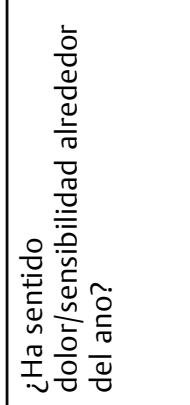 & 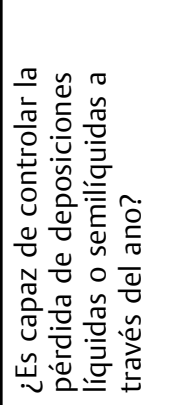 & 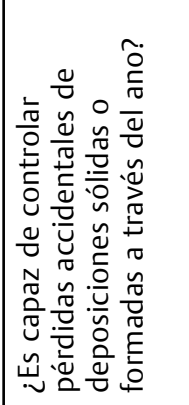 & 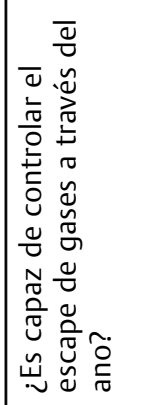 & 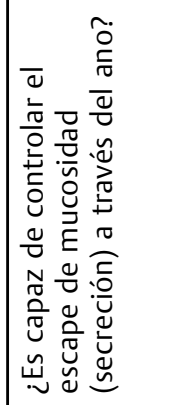 & 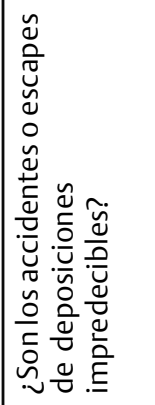 \\
\hline 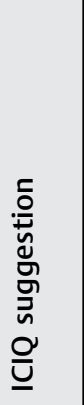 & 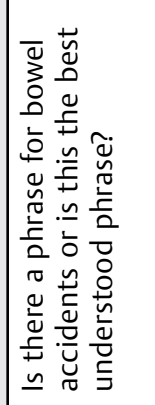 & 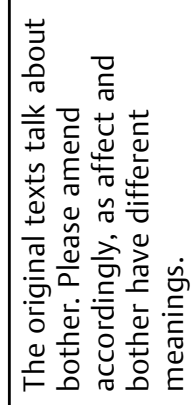 & 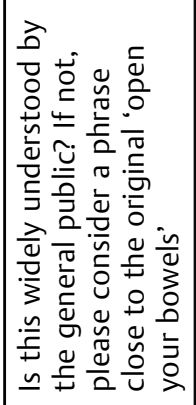 & 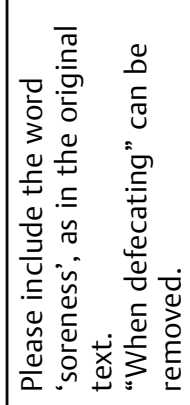 & 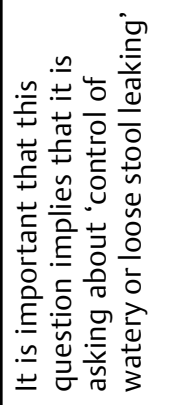 & 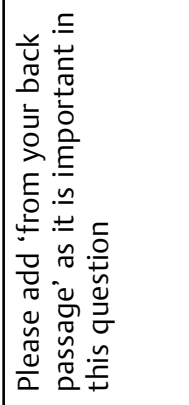 & 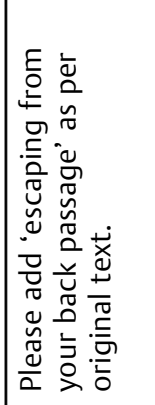 & 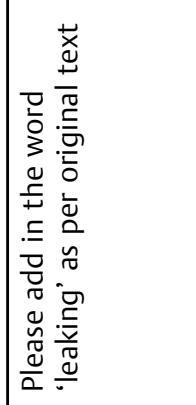 & 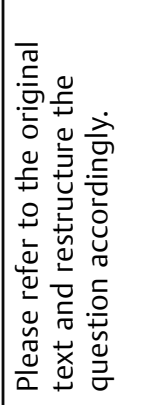 \\
\hline 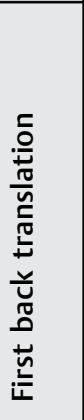 & 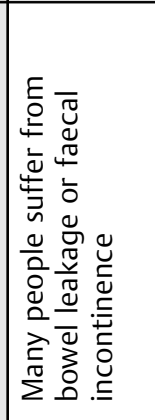 & 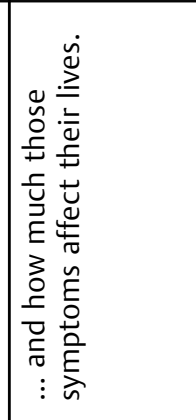 & 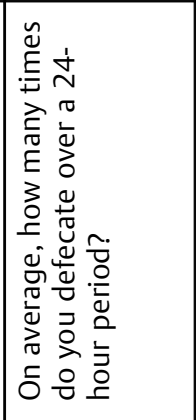 & 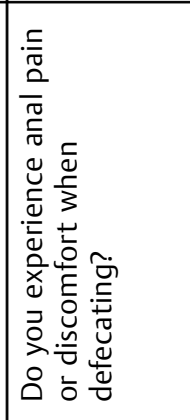 & 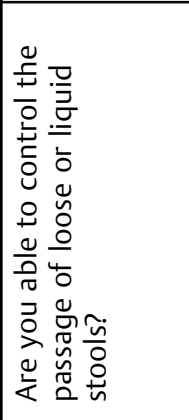 & 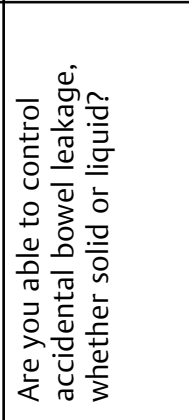 & 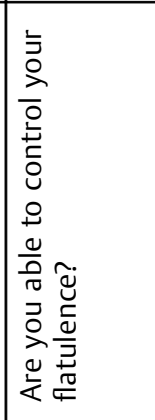 & 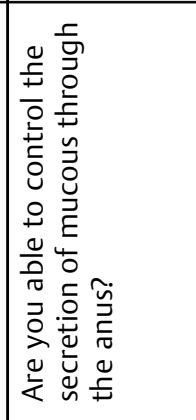 & 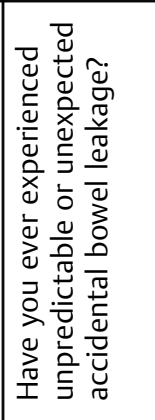 \\
\hline 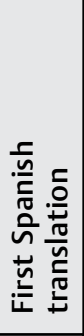 & 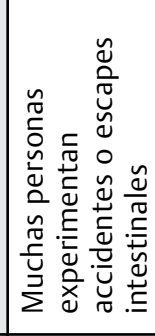 & 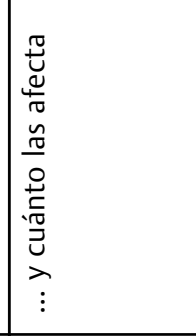 & 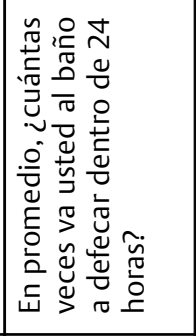 & 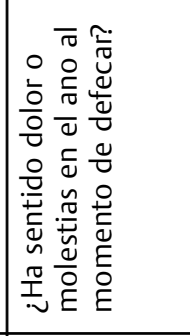 & 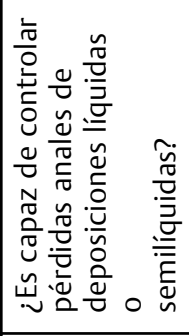 & 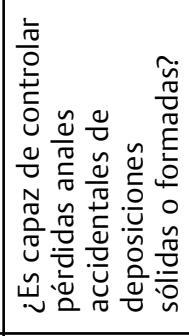 & 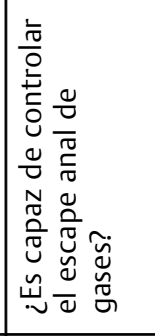 & 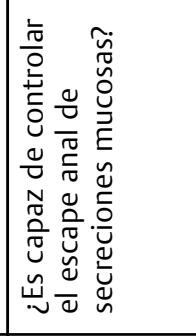 & 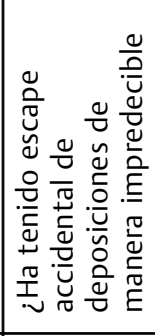 \\
\hline 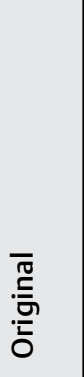 & 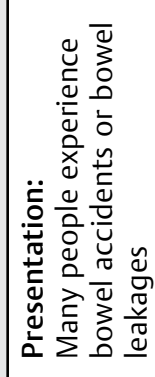 & 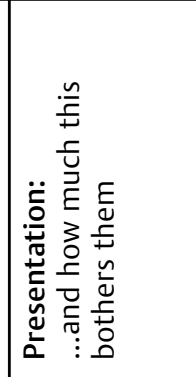 & 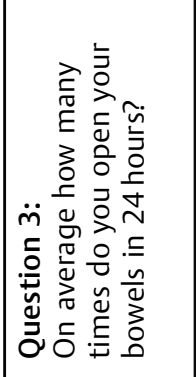 & 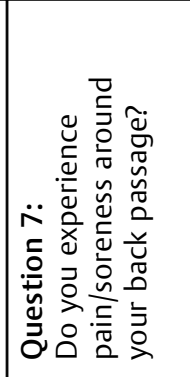 & 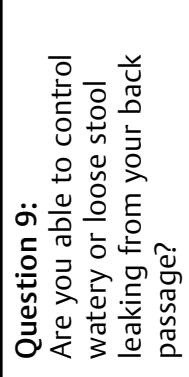 & 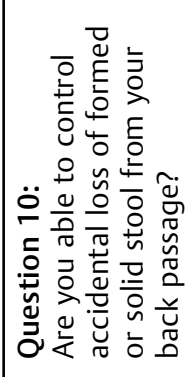 & 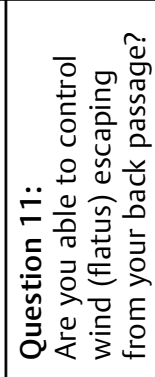 & 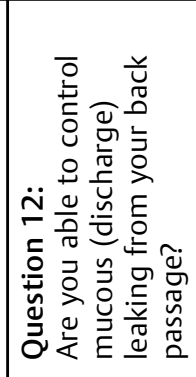 & 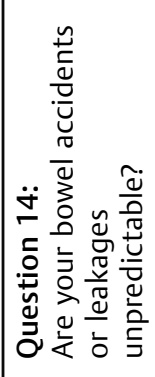 \\
\hline
\end{tabular}




\begin{tabular}{|c|c|c|c|c|}
\hline 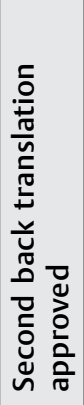 & & 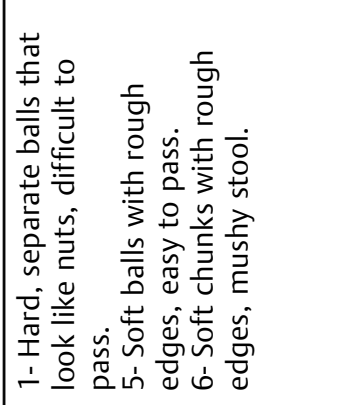 & 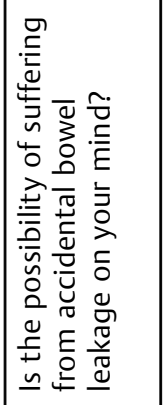 & 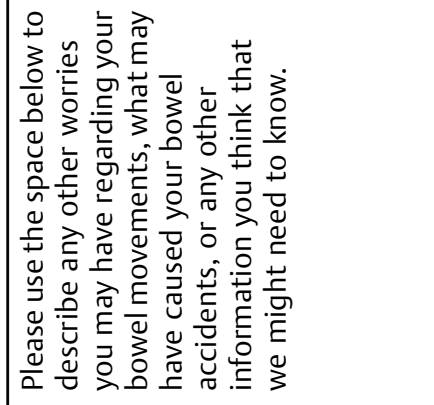 \\
\hline 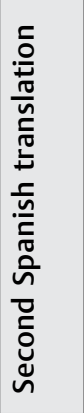 & & 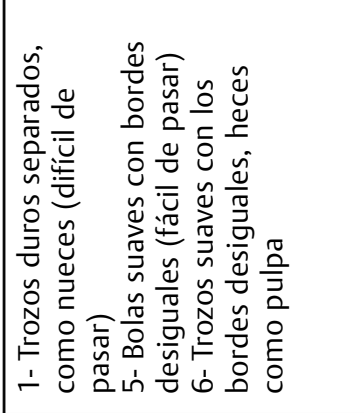 & 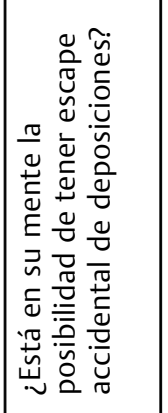 & 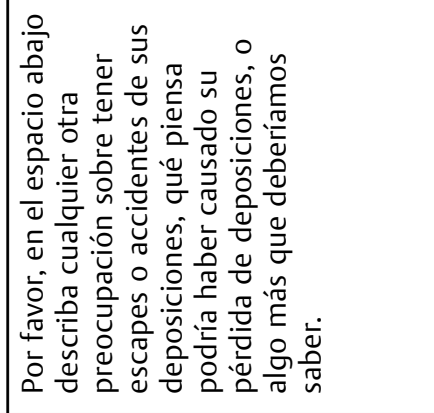 \\
\hline 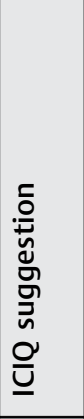 & & 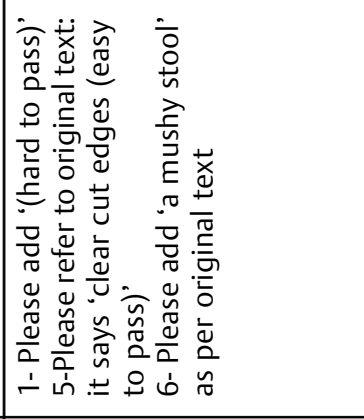 & 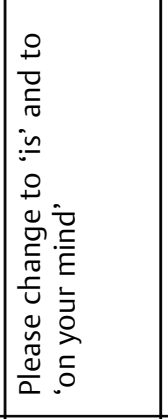 & 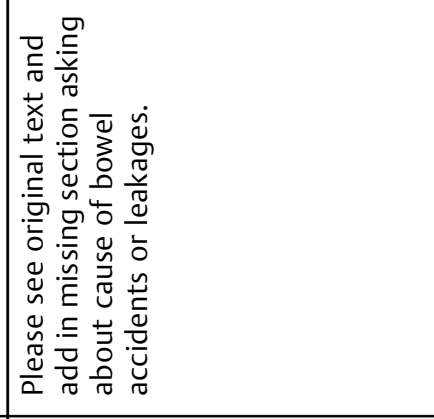 \\
\hline 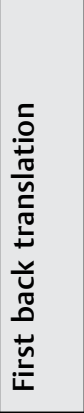 & & 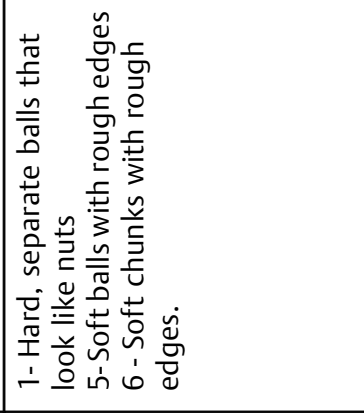 & 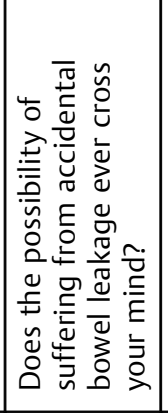 & 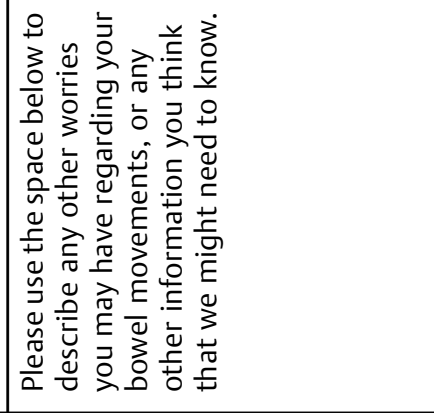 \\
\hline 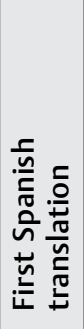 & 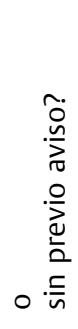 & 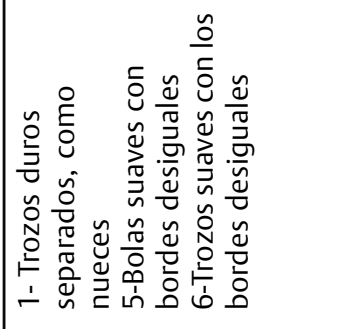 & 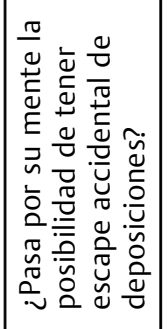 & 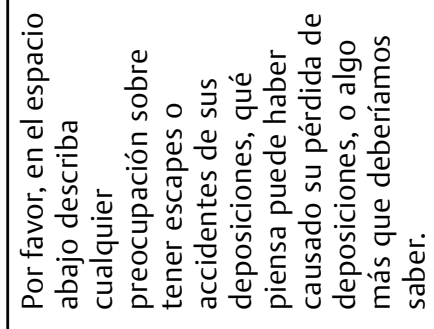 \\
\hline 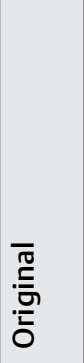 & & 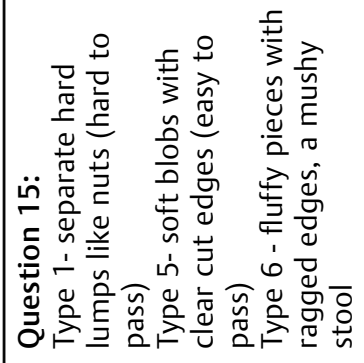 & 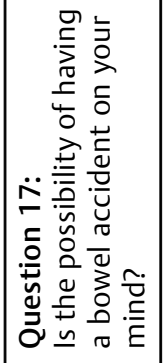 & 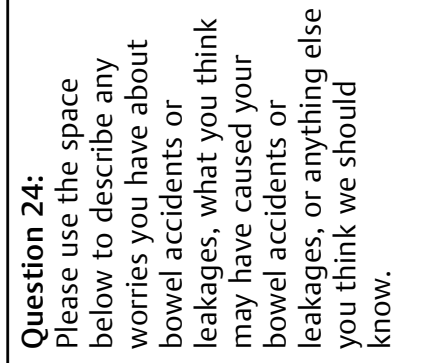 \\
\hline
\end{tabular}


Table 2 Sociodemographic and type of cancer characteristics of participants of the face validity assessment $(n=10)$

\begin{tabular}{|l|l|}
\hline Variable & $\mathbf{n}(\%)$ \\
\hline Gender & $7(70)$ \\
\hline Female & $3(30)$ \\
\hline Male & \\
\hline Age group (years) & $1(10)$ \\
\hline $50-59$ & $3(30)$ \\
\hline $60-69$ & $4(40)$ \\
\hline $70-79$ & $2(20)$ \\
\hline $80-89$ & \\
\hline Level of schooling & $2(20)$ \\
\hline Elementary (basic) education & $4(40)$ \\
\hline Technical & $4(40)$ \\
\hline Higher education & \\
\hline Marital status & $6(60)$ \\
\hline Married & $2(20)$ \\
\hline Divorced & $2(20)$ \\
\hline Single & $3(70)$ \\
\hline Type of cancer & \\
\hline Colon & \\
\hline Rectum & \\
\hline
\end{tabular}

sometimes $=32 \%$; most of the time $=12 \%$; always $=12 \%$ ), fecal incontinence (44\%), and flatus incontinence (76\%). Regarding QoL, 44\% reported feeling ashamed due to their bowels, worrying where toilets are (60\%), and restricting their social life (48\%).

\section{Discussion}

The present study resulted in a Spanish version of the ICIQ-B (supplementary file - available online), which was culturally adapted for the Chilean population after a process of translation and back translation and face validity assessment among colorectal cancer patients. This Spanish version demonstrated good testretest reliability, and might also be a reference for use in other Spanish-speaking countries. We recommend that before using this version of the questionnaire in other Spanish speaking countries, the authors proceed with a thorough review for cultural adaptation and linguistic validation. Although the Real Academia Española's (Royal Spanish Academy) main mission is to ensure that the changes that the Spanish language undergoes do not break its essential unity, there are some nuances and preferences of terminologies in each Spanish-speaking country.

In the present study, face validity analysis demonstrated that the ICIQ-B was adequate to cover the phenomenon "bowel function" among colorectal cancer patients. They reported that the final version was very clear and easy to understand, showing adequate face validity. Face validity
Table 3 Characterization of the participants of the test-retest reliability analysis $(n=15)$

\begin{tabular}{|c|c|}
\hline Variable & n (\%) \\
\hline \multicolumn{2}{|l|}{ Gender } \\
\hline Female & $8(53.3)$ \\
\hline Male & $7(46.7)$ \\
\hline \multicolumn{2}{|l|}{ Age group (years) } \\
\hline $50-59$ & $5(33.5)$ \\
\hline $60-69$ & 7 (46.9) \\
\hline $70-79$ & $2(13.4)$ \\
\hline $80-89$ & $1(6.7)$ \\
\hline \multicolumn{2}{|l|}{ Level of schooling } \\
\hline Elementary (basic) & $4(26.7)$ \\
\hline Secondary & $3(19.9)$ \\
\hline Technical & $4(26.7)$ \\
\hline Higher education & $4(26.7)$ \\
\hline \multicolumn{2}{|l|}{ Marital status } \\
\hline Married & $6(60)$ \\
\hline Divorced & $2(20)$ \\
\hline Single & $2(20)$ \\
\hline \multicolumn{2}{|l|}{ Type of cancer } \\
\hline Colon & $9(60)$ \\
\hline Rectum & $6(40)$ \\
\hline \multicolumn{2}{|l|}{$\begin{array}{l}\text { Eastern Cooperative Oncology Group } \\
\text { performance status }\end{array}$} \\
\hline 0 & $5(33.3)$ \\
\hline 1 & $9(60)$ \\
\hline 2 & $1(6.7)$ \\
\hline \multicolumn{2}{|l|}{ Cancer treatments received } \\
\hline Surgery & $8(53.3)$ \\
\hline Chemotherapy & $5(33.3)$ \\
\hline Radiotherapy & $3(20)$ \\
\hline
\end{tabular}

Note: Eastern Cooperative Oncology Group (ECOG) performance status: $0=$ fully active, able to carry on all predisease performance without restriction; 1 = restricted in physically-strenuous activity, but ambulatory and able to carry out work of a light or sedentary nature, such as, light house work, office work; 2 = ambulatory and capable of all selfcare, but unable to carry out any work activities; up and about more than $50 \%$ of waking hours.

with clinical experts on the subject has already been reported in the development phase of the original English version. $^{14}$

Compared with other questionnaires on bowel function, the ICIQ-B has a more wide-ranging approach, delving deeper into the domains of bowel pattern, bowel control, and QoL, as well as other bowel symptoms (stool format, straining, and sexual impact). In addition, the ICIQ-B may be used for a wider variety of health conditions that affect bowel function or bowel control, such as fecal incontinence. In turn, the colorectal module of the EORTC QLQ places more 
Table 4 Test-retest reliability analysis $(n=15)$

\begin{tabular}{|c|c|c|c|}
\hline Item/Domain & $\begin{array}{l}\text { Spearman } \\
\text { rho* }\end{array}$ & Item & $\begin{array}{l}\text { Spearman } \\
\text { rho* }\end{array}$ \\
\hline Bowel pattern score & 0.972 & $12 b$ & 1 \\
\hline Bowel control score & 0.996 & $13 a$ & 1 \\
\hline Quality of life score & 1 & $13 b$ & 1 \\
\hline $3 a$ & 1 & $14 a$ & 1 \\
\hline $3 b$ & 0.847 & $14 \mathrm{~b}$ & 1 \\
\hline $3 c$ & 0.967 & $15 a$ & 0.639 \\
\hline $4 a$ & 1 & $15 b$ & 0.910 \\
\hline $4 b$ & 1 & $16 a$ & 0.979 \\
\hline $5 a$ & 0.965 & $16 b$ & 1 \\
\hline $5 b$ & 1 & $17 a$ & 1 \\
\hline $6 a$ & 1 & $17 b$ & 1 \\
\hline $6 b$ & 1 & $18 \mathrm{a}$ & 1 \\
\hline $7 a$ & 0.842 & $18 \mathrm{~b}$ & 1 \\
\hline $7 b$ & 1 & 19a & 0.912 \\
\hline $8 a$ & 0.855 & $19 b$ & 0.961 \\
\hline $8 \mathrm{~b}$ & 1 & $20 a$ & 1 \\
\hline $9 a$ & 1 & $20 b$ & 1 \\
\hline $9 b$ & 1 & $21 a$ & 1 \\
\hline $10 a$ & 1 & $21 b$ & 1 \\
\hline $10 \mathrm{~b}$ & 1 & $22 a$ & 1 \\
\hline $11 a$ & 1 & $22 b$ & 1 \\
\hline $11 b$ & 1 & 23 & 1 \\
\hline $12 a$ & 1 & & \\
\hline
\end{tabular}

Note: ${ }^{*} p<0.001$

emphasis on QoL, but considers fewer items about bowel function. ${ }^{11,17}$ A previous retrospective study ${ }^{13}$ with rectal cancer patients undergoing surgical tumor resection reported that the EORTC QLQ-CR38 failed to identify clinically-consistent differences in bowel function among patient groups, as more technical aspects of rectal surgery that may be predictive of the functional outcome were not discriminated on the defecation subscale (for instance: type of anastomosis, level of anastomosis, and method of reconstruction). The authors ${ }^{13}$ hypothesized that this questionnaire may not be sensitive enough to detect functional differences after surgical treatment.

In the present study, the ICIQ-B showed good test-retest reliability: most of the items showed strong correlations. The only item that showed a moderate correlation between test and retest measures was item 15a. Stool form/texture probably changes more in one week depending on food intake, supplements, use of laxatives ${ }^{18}$ or mood. ${ }^{19}$

For this translation/validation study, we included colorectal cancer patients one month before and up to six months after the surgical tumor resection. They reported a variety of symptoms, including increased bowel movements, nocturnal bowel movement, fecal urgency, anal incontinence, and their impact on QoL due to embarrassment and restrictions to social life. The mean scores on the domains of the ICIQ-B (bowel pattern, bowel control, and QoL were similar to those reported in a study with people with bowel symptoms. ${ }^{15}$ These results are consistent with those of other studies, in which colorectal cancer patients usually complain of increased frequency of bowel movements that require planning to attend social events, ${ }^{20,21}$ the need to wear protective clothing, the need to get up at night to have a bowel movement, ${ }^{22}$ as well as fecal urgency and incontinence. ${ }^{5,23}$ These results reveal that colorectal cancer affects bowel function all through the different stages of diagnosis and treatment.

A systematic review ${ }^{20}$ indicated that most of the people living with colorectal cancer highlighted their need for more information about the long-term self-management of bowel symptoms (7\% to $89 \%$ ). In addition, due to social stigma and its association with old age, many patients are unwilling to notify symptoms of anal incontinence. ${ }^{14,24}$ Using validated questionnaires might be important to show the real magnitude of this problem and to stablish the effects of the proposed treatments.

\section{Study Limitations}

One limitation of the present study was the small sample size, which is inherent to this kind of study. For further research, the Spanish version of the questionnaire needs to be validated and analyzed regarding internal consistency with a larger sample, as the present study was just an initial step.

\section{Conclusions}

The Spanish version of the ICIQ-B has shown to be appropriate for use among colorectal cancer patients, and it has adequate face validity for target users and robust test-retest reliability. The ICIQ-B is a comprehensive and psychometrically strong patient-completed questionnaire to evaluate the symptoms of anal incontinence (including flatus incontinence) and their impact on QoL either for research purposes or the clinical practice. Furthermore, it may be used for many conditions that affect bowel function, such as colorectal cancer, inflammatory bowel disease, and fecal incontinence.

The ICIQ-B is a useful tool to assess bowel function and QoL among colorectal cancer patients. It will be useful for a variety of clinicians, including oncologists, gastroenterologists, physiatrists, nurses, physiotherapists, nutritionists, and psychologists, aiming to reduce the negative impact of bowel dysfunction on QoL.

The Chilean Spanish version of the ICIQ-B questionnaire is available as a Supplementary File (ICIQ-B Chilean Spanish Version\{hyperlink\}). The English version of this questionnaire will be made available upon request to ICIQ group (https://iciq.net/register) by clicking in "Request Modules." 


\section{Supplement}

(ICIQ-B Spanish Version - available online)

\section{Data Availability}

Data will be available upon request to corresponding author by email: csacomori@yahoo.com.br.

\section{Ethical Approval Statement}

The present study was approved by The Ethical Review Board from Servicio de Salud Metropolitano Oriente, Santiago de Chile (approval date: May 28, 2019).

\section{Author Contributions}

CS and LAL designed the study. PB translated it into Spanish. M.M, and J.P.S reviewed the Spanish versions. MP reviewed the back-translations and face validity suggestions. CS analyzed data and wrote the article. All of the authors revised the drafts, made substantial contributions, and approved the final version.

\section{Funding}

CONICYT CHILE, Fondecyt de Iniciación, number 11191016.

\section{Conflict of Interests}

Cinara Sacomori declares she received a grant for this research. None of the other authors declare any conflict of interests related to this research.

\section{Acknowledgments}

We would like to thank Edwin Abbett for performing the back translation, and the ICIQ group for all their support.

\section{References}

1 Bray F, Ferlay J, Soerjomataram I, Siegel RL, Torre LA, Jemal A. Global cancer statistics 2018: GLOBOCAN estimates of incidence and mortality worldwide for 36 cancers in 185 countries. CA Cancer J Clin 2018;68(06):394-424

2 Crosbie AB, Roche LM, Johnson LM, Pawlish KS, Paddock LE, Stroup AM. Trends in colorectal cancer incidence among younger adultsDisparities by age, sex, race, ethnicity, and subsite. Cancer Med 2018;7(08):4077-4086

3 Yin L, Fan L, Tan R, et al. Bowel symptoms and self-care strategies of survivors in the process of restoration after low anterior resection of rectal cancer. BMC Surg 2018;18(01):35

4 Tan SH, Liao YM, Lee KC, Ko YL, Lin PC. Exploring bowel dysfunction of patients following colorectal surgery: A cohort study. J Clin Nurs 2019;28(9-10):1577-1584

5 John SKP, George S, Primrose JN, Fozard JBJ. Symptoms and signs in patients with colorectal cancer. Colorectal Dis 2011;13(01):17-25

6 Grasso M, Cimmino A, Sangiuliano N, Niglio A. How to save both transverse colon and continence after extensive left colon surgery: A case report of a new procedure. Int J Surg Case Rep 2018; 47:64-66. Doi: 10.1016/j.ijscr.2018.04.015

7 Croese AD, Lonie JM, Trollope AF, Vangaveti VN, Ho Y-H. A metaanalysis of the prevalence of Low Anterior Resection Syndrome and systematic review of risk factors. Int J Surg 2018;56:234-241. Doi: 10.1016/j.ijsu.2018.06.031

8 Mayer DK, Gerstel A, Walton AL, et al. Implementing survivorship care plans for colon cancer survivors. Oncol Nurs Forum 2014;41 (03):266-273
9 van der Sande ME, Hupkens BJP, Berbée M, et al. Impact of radiotherapy on anorectal function in patients with rectal cancer following a watch and wait programme. Radiother Oncol 2019; 132:79-84. Doi: 10.1016/j.radonc.2018.11.017

10 Lim JF, Tjandra JJ, Hiscock R, Chao MWT, Gibbs P. Preoperative chemoradiation for rectal cancer causes prolonged pudendal nerve terminal motor latency. Dis Colon Rectum 2006;49(01): 12-19

11 Whistance RN, Conroy T, Chie W, et al; European Organisation for the Research and Treatment of Cancer Quality of Life Group. Clinical and psychometric validation of the EORTC QLQ-CR29 questionnaire module to assess health-related quality of life in patients with colorectal cancer. Eur J Cancer 2009;45(17):3017-3026. Doi: 10.1016/j.ejca.2009.08.014

12 Eypasch E, Williams JI, Wood-Dauphinee S, et al. Gastrointestinal Quality of Life Index: development, validation and application of a new instrument. Br J Surg 1995;82(02):216-222

13 Neuman HB, Schrag D, Cabral C, et al. Can differences in bowel function after surgery for rectal cancer be identified by the European Organization for Research and Treatment of Cancer quality of life instrument? Ann Surg Oncol 2007;14(05): 1727-1734

14 Cotterill N, Norton C, Avery KNL, Abrams P, Donovan JL. A patientcentered approach to developing a comprehensive symptom and quality of life assessment of anal incontinence. Dis Colon Rectum 2008;51(01):82-87

15 Cotterill N, Norton C, Avery KNL, Abrams P, Donovan JL. Psychometric evaluation of a new patient-completed questionnaire for evaluating anal incontinence symptoms and impact on quality of life: the ICIQ-B. Dis Colon Rectum 2011;54(10):1235-1250

16 Markland AD, Burgio KL, Beasley TM, David SL, Redden DT, Goode PS. Psychometric evaluation of an online and paper accidental bowel leakage questionnaire: The ICIQ-B questionnaire. Neurourol Urodyn 2017;36(01):166-170

17 Calvo Ó, Oliveros R, Sánchez R. Adaptación cultural del formulario EORTC QLQ CR-29 para su aplicación en pacientes con cáncer de recto en el Instituto Nacional de Cancerología de Colombia. Rev Colomb Cancerol 2010;14:189-198. Doi: 10.1016/S0123-9015 (10)70082-2

18 Ansell J, Butts CA, Paturi G, et al. Kiwifruit-derived supplements increase stool frequency in healthy adults: a randomized, doubleblind, placebo-controlled study. Nutr Res 2015;35(05):401-408. Doi: 10.1016/j.nutres.2015.04.005

19 Ballou S, Katon J, Singh P, et al. Chronic Diarrhea and Constipation Are More Common in Depressed Individuals. Clin Gastroenterol Hepatol 2019;17(13):2696-2703

20 Kotronoulas G, Papadopoulou C, Burns-Cunningham K, Simpson $\mathrm{M}$, Maguire R. A systematic review of the supportive care needs of people living with and beyond cancer of the colon and/or rectum. Eur J Oncol Nurs 2017;29:60-70. Doi: 10.1016/j. ejon.2017.05.004

21 Lu LC, Huang XY, Chen CC. The lived experiences of patients with post-operative rectal cancer who suffer from altered bowel function: A phenomenological study. Eur J Oncol Nurs 2017; 31:69-76. Doi: 10.1016/j.ejon.2017.10.004

22 Atherton PJ, Halyard MY, Sloan JA, et al. Assessment of patientreported measures of bowel function before and after pelvic radiotherapy: an ancillary study of the North Central Cancer Treatment Group study N00CA. Support Care Cancer 2013;21 (04):1193-1199

23 van Heinsbergen M, Janssen-Heijnen ML, Leijtens JW, Slooter GD, Konsten JL. Bowel dysfunction after sigmoid resection underestimated: Multicentre study on quality of life after surgery for carcinoma of the rectum and sigmoid. Eur J Surg Oncol 2018;44 (08):1261-1267. Doi: 10.1016/j.ejso.2018.05.003

24 Johanson JF, Lafferty J. Epidemiology of fecal incontinence: the silent affliction. Am J Gastroenterol 1996;91(01):33-36 